\title{
Présentation des journées d'étude
}

\section{Sophie Jugie et Claire Barbillon}

\section{OpenEdition}

Journals

Édition électronique

URL : https://journals.openedition.org/cel/20495

DOl : $10.4000 / \mathrm{cel} .20495$

ISSN : 2262-208X

Éditeur

École du Louvre

\section{Référence électronique}

Sophie Jugie et Claire Barbillon, « Présentation des journées d'étude », Les Cahiers de l'École du Louvre [En ligne], 17 | 2021, mis en ligne le 26 novembre 2021, consulté le 13 décembre 2021. URL : http:// journals.openedition.org/cel/20495; DOI : https://doi.org/10.4000/cel.20495

Ce document a été généré automatiquement le 13 décembre 2021.

\section{c.) (i) ()}

Les Cahiers de l'École du Louvre sont mis à disposition selon les termes de la licence Creative Commons Attribution - Pas d'Utilisation Commerciale - Pas de Modification 4.0 International. 


\title{
Présentation des journées d'étude
}

\author{
Sophie Jugie et Claire Barbillon
}

1 Au-delà de la conservation de la collection de sculptures du musée du Louvre de la fin de l'Antiquité au milieu du XIX siècle, le département des Sculptures a pour mission d'étudier et de documenter les sculptures des collections nationales de la même période. Grâce à la documentation qu'enrichissent quotidiennement les conservateurs et documentalistes du département, mais qui accueille aussi les travaux que lui confient d'autres chercheurs, le département a la chance de disposer du temps et de la mémoire, ce qui rend possible la reprise de questionnements anciens et la réactivation d'enquêtes interrompues.

2 C'est ainsi que le Recueil général des monuments sculptés en France pendant le haut Moyen Âge (IV ${ }^{e} X^{e}$ siècles) renaît aujourd'hui après une interruption de plus de trente ans. Entrepris sous l'égide de Jean Hubert par une équipe du Centre national de la recherche scientifique, du milieu des années 1960 au milieu des années 1980, cette enquête avait abouti à la constitution d'une documentation considérable, dont la publication par le Comité des travaux historiques et scientifiques s'était arrêtée après la parution de quatre volumes portant sur sept départements.

3 Alors que plusieurs pays d'Europe ont entrepris également l'inventaire des édifices, des sculptures et des peintures de cette période si déterminante de la fin de l'Antiquité et du haut Moyen Âge, il était indispensable de reprendre cet inventaire pour la France, avec les outils et les méthodes de notre temps. C'est ainsi, en s'appuyant sur la recherche académique la plus actuelle, que s'est constitué le programme de recherche SATHMA (acronyme de Sculpture de l'Antiquité tardive et du haut Moyen Âge), qui associe le département des Sculptures du musée du Louvre, le centre de recherche de l'École du Louvre et les UMR 6298 - ArTeHis de l'Université de Bourgogne et 5138 Archéologie et Archéométrie de l'Université de Lyon.

4 Le premier objectif du programme a été de concevoir une plateforme numérique pour rendre accessibles en ligne, aux spécialistes comme au public intéressé, les informations sur ces monuments, issues de la documentation encore inédite déposée au département des Sculptures comme des recherches en cours. 
Il était indispensable, une fois déterminés les objectifs et les partenaires du programme SATHMA, de confronter notre démarche avec celle des autres pays européens, tant il est vrai que nos frontières actuelles n'ont guère de sens pour ces époques : c'est à ce moment d'échange qu'ont été conviés les chercheurs, lors des journées des 24 et 25 septembre 2020 à l'École du Louvre, pour parler historiographie, méthodes d'analyse et datation des œuvres, publications papier et corpus en ligne.

7 L'engagement de l'École du Louvre dans le programme de recherche SATHMA est exemplaire à plus d'un titre. D'une part parce que s'y consacre depuis plusieurs années Anne-Bénédicte Mérel-Brandenburg, membre permanent de l'Équipe de recherche de l'École du Louvre, dont c'est le champ de compétence directe puisque sa thèse de doctorat portait sur cette période, en Languedoc méditerranéen et Roussillon. D’autre part parce qu'il associe l'École au Musée du Louvre - en l'occurrence le département des sculptures, grâce à la co-direction du programme par Pierre-Yves Le Pogam, association naturelle et fondamentale. Enfin parce qu'il lie aussi ces chercheurs à ceux du CNRS et de l'université (UMR 6298 - ArTeHIS, MSH Dijon et UMR 5138 - ArAr, Université Lyon).

8 Les journées d'étude qui se sont tenues les 24 et 25 septembre 2020, à l'amphithéâtre Michel-Ange de l'École du Louvre et à l'auditorium du musée du Louvre, ont été également exemplaires par la présence de nombreux chercheurs de différentes générations, archéologues, historiens de la sculpture, spécialistes des humanités numériques, réunis, virtuellement ou physiquement, entre deux confinements, alors que les conditions sanitaires imposaient des contraintes complexes. Sur la question méthodologique des corpus, sur les thèmes du rapport avec l'architecture, des formes et des datations, sur les matériaux et les techniques, les communications ont été riches et ont croisé les points de vue de chercheurs issus, il convient de le signaler et de s'en réjouir, de différents pays d'Europe. On ne saurait aussi oublier un des aspects principaux du programme SATHMA, qui a fait l'objet de la table ronde conclusive de ces journées : l'intérêt et les enjeux d'un corpus en ligne.

Que tous soient remerciés pour leur participation, leur rôle facilitateur et enfin pour cette publication très rapide, un an après la tenue des journées d'étude. Les Cahiers de l'École du Louvre sont fiers de publier ainsi, dans leur $17^{\mathrm{e}}$ numéro, le fruit des recherches récentes sur une période féconde en découvertes et stimulante pour la connaissance de l'art et des sociétés de plus de sept siècles de l'histoire européenne comme pour l'expérimentation de méthodes contemporaines qui sont celles des humanités numériques.

\section{AUTEURS}

\section{SOPHIE JUGIE}

Directrice du département des Sculptures du musée du Louvre 


\section{CLAIRE BARBILLON}

Directrice de l'École du Louvre 